\title{
Pain, Physical Dependence and Pseudoaddiction: Redefining Addiction for 'Nice' People?
}

\author{
Kirsten Bell \& Amy Salmon
}

NOTICE: this is the accepted version of a work that was accepted for publication in International Journal of Drug Policy. Changes resulting from the publishing process, such as peer review, editing, corrections, structural formatting, and other quality control mechanisms may not be reflected in this document. Changes may have been made to this work since it was submitted for publication. A definitive version was subsequently published in International Journal of Drug Policy, 2009, volume 20, issue 2, pages 170178. DOI: http://dx.doi.org/10.1016/j.drugpo.2008.06.002

\begin{abstract}
Backgound: The undertreatment of pain has increasingly been framed as both a public health problem and a human rights issue. The application of rights-based discourses to the field of pain management has provided an important means of critiquing "opiophobia" amongst healthcare professionals and challenging current criminal-legal and regulatory sanctions on the distribution of opiate medications. This movement would therefore appear to align with harm reduction advocacy and longstanding criticisms of international drug policies. However, discourses on pain management rest on moral as well as medical assumptions about who has pain and who needs drugs. Methods: In this paper, we critically examine discourses on pain management and addiction exemplified in academic and clinical literature produced by and for physicians providing guidance on the provision of opiates for the relief of chronic pain. Results: Our analysis reveals that discourses on pain management and the right to pain relief reify distinctions between the 'deserving pain patient' and the 'undeserving addict', serving both to further stigmatise people labelled as 'addicts' and delegitimise claims to pain they might voice.

Conclusion: Present efforts to secure access to pain relief as a human right are likely to undermine, rather than advance, the rights of so-called 'drug addicts'.
\end{abstract}


It's a fine line between pleasure and pain

You've done it once you can do it again

Whatever you done don't try to explain

It's a fine, fine line between pleasure and pain

- Divinyls

\section{Introduction: Reframing Pain Management as a Human Right}

Since the 1980s health care professionals have been aware of widespread shortfalls in the treatment of cancer and non-cancer pain (Weissman, Gutman \& Dahl, 1991; Elliott \& Elliott, 1992; Sun et al., 2007; Brennan, Carr \& Cousins, 2007). In an effort to respond to these deficiencies, and in light of emerging evidence that opioid analgesics provide an effective form of relief for certain types of intractable pain (WHO, 1986; Portenoy, 1996; Nicholson \& Passik, 2007; Katz et al., 2007), the past two decades have seen an increase in the medical use of opioids to treat both cancer and chronic pain (Højsted \& Sjøgren, 2007).

However, in spite of growing concern with standards of care for pain treatment and widespread support for improved pain control, the undertreatment of pain continues to be a serious public health issue (Rich, 2000; Gilson \& Joranson, 2002; Glajchen, 2001; Green, Wheeler \& LaPorte, 2003; Cheattle \& Gallagher, 2006; Bhamb et al., 2007; Fishman, 2007; Frantsve, 2007; Brennan, Carr, \& Cousins, 2007). Three factors are generally emphasised in the academic and clinical literature as responsible for the continuing undertreatment of pain. First, many physicians lack technical competence in effective pain management because they are inadequately trained in this area (Brennan, Carr \& Cousins, 2007). Second, clinicians and researchers have identified attitudinal barriers which exist among practitioners, who are sometimes viewed as unduly concerned with the potential dangers of prescribing opiate medications (e.g. morphine, oxycodone, codeine and fentanyl) for pain - a fear termed "opiophobia" by some commentators (Elliott \& Elliott, 1992; Sees \& Clark, 1993; Rich, 2000; Brennan, Carr \& Cousins, 2007).

A third key barrier is the criminal-legal and regulatory restrictions governing physicians' abilities to prescribe opiate medications (Brennan, Carr \& Cousins, 2007; IASP/EFIC, 2004). Specifically, the US-led "war on drugs", bolstered by international conventions and agencies concerned with the control of narcotic drugs, has created an environment in which access to opiate drugs of all types is tightly controlled and highly surveilled in their manufacture, import and circulation (Brewley-Taylor, 2005). Consequently, physicians in many countries are required to register and receive an exemption to laws governing the traffick of narcotics by a government regulatory agency in order to prescribe opiate drugs, and records of physicians' prescriptions of these medications are closely and uniquely monitored by the state (Brennan, Carr \& Cousins, 2007). Indeed, there have been a number of highly publicised cases whereby physicians treating patients for pain (including terminally-ill cancer patients) have been arrested and jailed for violating laws pertaining to the 'appropriate' prescription of pain medications (see Brennan, Carr \& Cousins, 2007 for a discussion). These encroachments on physicians' 
abilities to prescribe opiates have been of considerable concern to many members of the profession (Fishman, 2005a, Fishman, 2005b), and may be at least partially related to an increasing level of physician interest in rights-based discourses (see Fishman, 2007).

Building on established standards of care for pain treatment and widespread support for improved pain control, a group of pain clinicians and researchers have recently begun to frame access to pain management through the lexicon of human rights (Fishman, 2007; Brennan, Carr \& Cousins, 2007). A declaration by the International Association on the Study of Pain (IASP), the European Federation of IASP Chapters (EFIC), and the World Health Organization emphasises the legitimacy of pain as an urgent public health issue, its negative impact on quality of life, and the social and economic costs for individuals and societies when pain is undertreated. It also calls on government and international agencies to support the view that "the relief of pain should be a human right", and to improve access to pain relief in medical settings (IASP/EFIC, 2004).

However, the pain management movement as a whole relies on a very rigid distinction between the 'legitimate' use of 'medication' to ease pain and the 'illegitimate' use of 'drugs' by 'junkies' (see Schuster, 1989). As criminologist Neil Boyd notes, in the current criminal-legal relevancies of the war on drugs, "the taking of medication is socially acceptable; the taking of drugs is not" (cited in Boyd, 2004: 67; emphasis ours). Because opiate analgesics are both 'useful medications' and 'abusable drugs', "maintaining the line between the proper use and harmful misuse of [such] psychoactive substances requires careful discursive and practical management" (Keane, 2008: 5).

In this paper, we explore the discursive and practical management of the line between the 'proper' and 'improper' use of pain medications. Accordingly, the key questions we focus on are: what is the relationship between pain management and addiction and how are physicians entreated to respond to it in practice? How are 'addicts' constructed in pain management discourses and what implications does this have for their access to pain relief? To this end, we argue that recent efforts to frame access to opiate analgesics as a critical tool in optimising pain relief have rested on problematic assumptions about who has pain and who needs drugs, which explicitly reify the marginalisation of people labelled 'drug addicts'.

\section{Methodology}

In this paper, we critically examine the discourses on pain management and addiction exemplified in published academic and clinical literature. It is important to note at the outset that there is no unitary theoretical framework or methodology for critical discourse analysis (van Dijk, 1999; Antaki et al., 2003; McGregor, 2003). Rather, "Discourse analysis is best seen as an umbrella term covering a wide range of different approaches and traditions" (Martin \& Stenner, 2004: 399). Our approach draws on Michel Foucault's (1980, 1991, 1994, 2002) theorisation of the conceptual terrains (or 'discourses') through which knowledge is formed and produced. For Foucault, discourses are fundamentally linked to the exercise of power: discourse is both constituted by and ensures the reproduction of social systems through forms of selection, exclusion and domination which are normalised and naturalised in language (Young, 
1981; Hook, 2001). Hence, we have chosen to examine discourses on pain management and addiction through micro-level texts, linking them with macro-level discursive practices. Following Acevedo (2007), it is not our intention to prove or disprove the veracity of discourses regarding pain management and addiction produced in these texts. Instead our interest lies in determining how these discourses actually create, define or construct 'addiction' and, by implication, 'addicts'.

Key literature for our analysis was found through inputting the word 'addiction' into the search engines of highly regarded pain management journals, including: the Journal of Pain and Symptom Management, the Clinical Journal of Pain, the Journal of Pain, the European Journal of Pain, Pain Medicine and Pain. Additional references were found through citation chasing. Whilst recognising that a variety of healthcare professionals are involved in pain management, and a variety of texts would lend themselves to a critical discourse analysis on this topic, we have chosen to focus on published, peer-reviewed literature written by and for physicians, as it is physicians who are generally perceived to have primary responsibility for mediating patients' access to prescription pain medications (see IASP/EFIC, 2004).

\section{An Addict by any Other Name: De-linking Dependence and Addiction}

One of the salient challenges identified in the literature on overcoming opiophobia among clinicians and ensuring improved access to pharmacological treatment for pain has been the perceived need to separate clinically and discursively the spectre of 'addiction' from the 'natural' consequences of 'proper' use of opioid medications by 'legitimate' patients. To illustrate, specialists in pain medicine emphasise "the important difference between the natural, physiological dependence that develops to opioid analgesics and the pathological psychological dependence that characterizes addiction" (Rich, 2000: 64, emphasis ours; see also Sees \& Clark, 1993; Portenoy, 1996; Heit, 2001; Cohen et al., 2002; Savage, 2002; Kirsch et al., 2002; Adams et al., 2004; Nicholson \& Passik, 2007; APS, 2007; Højsted \& Sjøgren, 2007). This distinction is underscored in the following statement by a former director of the National Institute on Drug Abuse: "The confusion between the use of narcotics by street addicts [and the use of opioid analgesics by people with chronic pain] influences the attitudes and behavior of dispensing practitioners, patients, and their families, as well as government policymakers who regulate the availability of these drugs" (Rich 2000: 64; emphasis ours). In this respect, the behaviour of the 'illegitimate' drug user or "street addict" is seen not only as conceptually and behaviourally separate from that of the 'legitimate' (prescribed) drug user, but is, in fact, viewed as an impediment to achieving optimal pain management of 'real' pain patients.

To achieve this distinction between the deserving pain patient and the undeserving addict, definitions of addiction in the field of pain management separate the physical and psychological components of the DSM-IV definitions of 'substance use disorders' and 'dependence' (see APS, 2007). To further consolidate a conceptual separation between dependence and addiction, pain researchers have argued that while physical dependence does develop with the use of medically-prescribed opioids, it is not generally accompanied by other features of substance 'abuse'. This has led to growing physician calls to replace the word 'dependence' with 'addiction' in the DSM-V, so that patients 
requiring pain medication will no longer be "made to suffer" because clinicians, misled by the DSM-IV, confuse their tolerance and withdrawal symptoms with addiction (O'Brien, Volkow, \& Li, 2006: 764). Implicit in this critique is the reality that an 'addict' identity is a legitimate source of suffering which supersedes any other claim to "suffering" (such as chronic pain) an individual so identified might advance. By contrast, those with a physiological dependence risk suffering not by virtue of their biology, medical condition, or behaviour, but in being mistaken for an 'addict'. This suffering on the basis of a "spoiled identity" (Goffman, 1962) is thus seen as illegitimate only when it is misattributed.

\section{Physical Dependence \& Chronic Pain: Deconstructing or Stigmatising Addiction?}

The experiences of clinicians and researchers working in the pain management field would appear to pose a challenge to mainstream understandings of addiction, where compulsive efforts on the part of the individual to get high and avoid withdrawal are often deemed a critical and defining constituent. As Room (2003: 227) notes, "in thinking about heroin, the classic image of the 'monkey on the back', the need for the drug arising out of the fear of going into withdrawal, has often been seen as all that needs to be known to understand addiction". However, instead of challenging the paradigm of addiction itself, the general tendency evident in the literature has been to merely pull apart the physiological and psychological components of this concept. In this way, not only does the hegemonic paradigm of addiction remain intact, it becomes a method of destigmatising pain patients in and through justifications for withholding or providing sub-optimal pain management to those labelled as 'real addicts'. For example, Gilson and Joranson (2002: S94) note, "misuse of terminology relating to pain and addiction has the potential to mislabel pain patients as 'addicts' and, thus, to interfere with their pain treatment". That an attribution of 'addiction' may also interfere with the pain treatment of those so labelled is not of apparent concern.

Much of the discourse on access to pain relief explicitly restigmatises and marginalises addiction and 'addicts'. For example, Passik (2001: 360) asserts, "because 6 to 15\% of the U.S. population abuses drugs, the history of pain management is marked by the undertreatment of the other 85 to $94 \%$ of the population". The implications of Passik's analysis are that the $6-15 \%$ of the population who 'abuse' drugs must either have their pain adequately (if incidentally) controlled by the drugs they take, or, more likely, are not in a position to advance legitimate claims for access to medical treatment for pain because they 'abuse' drugs. Indeed, US Senator Susan Collins has stated, "It is tragically ironic that, while our streets are awash with prescription medications, the undertreatment of pain in legitimate patients remains a national problem" (in Katz et al., 2007; emphasis ours). The outcome is clear: the bid to legitimise of the claims of one population to pain medication comes at the price of delegitimising and restigmatising another.

Although definitive evidence to support the claim is lacking, the hegemonic position in the literature is that chronic pain patients with a history of problematic substance use are at higher risk for addiction to opioid analgesics than other groups (Portenoy, 1996; Cohen et al., 2002; Weaver \& Schnoll, 2002; Michna et al., 2004; Nicholson \& Passik, 2007). Nevertheless, a number of clinicians and researchers have argued that it is unnecessary 
and inhumane to exclude chronic pain patients with histories of addiction from receiving opioid medications (see Dunbar \& Katz, 1996; Passik, 2001; Cohen et al., 2002; Gilson \& Joranson, 2002; Weaver \& Schnoll, 2002). As Passik (2001: 360) notes, "A blanket contraindication like this would represent nothing more than a blatant commitment to the undertreatment of these patients [with a history of addiction]".

However, most clinicians agree that differential treatment of current, former or 'at risk' addicts is warranted, suggesting that these patients should be carefully monitored to ensure that addiction does not (re)occur as a consequence of treatment with opiates. Measures commonly suggested in this literature for surveilling opiate use include: requiring regular urine drug screens, increasing the frequency of office visits, providing only a very limited supply of medication at any one time, regular pill or patch counts, witnessed dosing (usually at a pharmacy or medical clinic), use of an opioid agreement, and adjuvant psychotherapy or required attendance at Alcoholics or Narcotics Anonymous (Passik, 2001; Cohen et al. 2002; Kirsh et al., 2002; Lipman, 2005; Nicholson \& Passik, 2007).

\section{Pain, Addiction and Undertreatment: The Emergence of 'Pseudoaddiction'}

The need to separate out the 'legitimate' pain patient from the 'drug seeking addict' becomes further apparent in the concept of 'pseudoaddiction'. According to the American Pain Society (2007):

Pseudoaddiction is a term which has been used to describe patient behaviors that may occur when pain is undertreated. Patients with unrelieved pain may become focused on obtaining medications, may 'clock watch,' and may otherwise seem inappropriately 'drug seeking.' Even such behaviors as illicit drug use and deception can occur in the patient's efforts to obtain relief. Pseudoaddiction can be distinguished from true addiction in that the behaviors resolve when pain is effectively treated (emphasis ours).

Weissman and Haddox (1989) first introduced the term pseudoaddiction to describe the behaviours of a 17-year-old man with acute leukaemia who began to exhibit progressively escalating pain behaviour and assertively requesting additional medication for its relief. Medical staff were unconvinced of his claims and suspected that he had become 'addicted' to his pain medication; however, Weissman and Haddox (1989) argued that this patient manifested an "iatrogenic syndrome" caused by inadequate pain management, whereby a patient starts to develop abnormal behaviours that appear very similar to "idiopathic opioid psychological dependence". Although it is often expanded well beyond its original use (Weissman, 1994), the concept of 'pseudoaddiction' has been widely taken up in the pain management literature and has become a standard way of explaining 'aberrant behaviours' which look like, but should not be interpreted as, 'addiction' in the context of both chronic and cancer pain management (see Passik et al., 2000; Heit, 2001; Cohen et al., 2002; Savage, 2002; Kirsch et al., 2002; Elander et al., 2004; Nicholson \& Passik, 2007; APS, 2007; Passik \& Kirsch, 2007; Ziegler, 2007).

Pseudoaddiction is a phenomenon that is difficult to empirically demonstrate (Nicholson \& Passik, 2007: 1003). Indeed, it can only be diagnosed ex post facto. In other words, 
the defining features of pseudoaddiction as an iatrogenic syndrome can only be recognised when pain is adequately relieved and the 'pseudoaddictive' behaviours disappear. Thus, according to the American Pain Society (2007), "Addiction in the course of opioid therapy for pain can best be assessed after the pain has been brought under adequate control, though this is not always possible." Nicholson and Passik (2007: 1032) similarly note, "Adequate pain relief eliminates the abnormal behavior, and this differentiates pseudoaddiction from true addiction" (see also Weissman \& Haddox, 1989; Sees \& Clark, 1993; Heit, 2001; Savage, 2002; Højsted \& Sjøgren, 2007). The possibility of 'pseudo-addiction' is seen to create a dilemma for the clinician, who must ask him or herself: "is the observed behavior due to inadequate pain control or is it a manifestation of addiction?" (Dunbar \& Katz, 1996: 268).

This creates a significant problem for physicians who need to make decisions about whether to prescribe opiate drugs for pain, because those decisions are typically made in the context of interactions with patients claiming to have current, unrelieved and chronic pain. The physician encountering such pain complaints faces a quandary: one can only determine whether a patient is an 'addict' or a 'pseudoaddict' if medication to relieve pain is provided and effective. However, medication is only to be provided (and thus can only have a chance to be effective) if the physician believes that the patient is not an addict, but a pseudoaddict. Consequently, when trying to decide whether a patient is an 'addict' or a 'pseudoaddict' (and therefore whether to provide medication or not), the clinician must discern the intent of the drug-seeking behaviours (Kirsch et al., 2002) and ascertain whether patients are being "truthful" about their subjective claims of pain (Passik \& Kirsch, 2007).

Clinicians' values and assumptions about who is likely to abuse pain medications inform decisions to treat or not treat a pain complaint. There is evidence of endemic undertreatment of pain in certain populations, such as sickle cell disease patients of African or Caribbean origin (see Elander et al., 2003, 2004) and prisoners with cancer (Lin and Mathew 2005). Researchers in these contexts observe that undertreatment of pain in these populations occurs primarily due to prejudicial and racist stereotypes suggesting high levels of substance abuse amongst these groups. Work with HIV/AIDS patients (Passik et al., 2000; Kirsch et al., 2002) also demonstrates a heightened risk for undertreatment of pain in this population. This suggests that the label of 'pseudoaddiction' may be more readily applied to pain patients who are white, middle class, and do not have a history of problematic substance use than to patients from less privileged backgrounds who have (or are believed to have) such a history.

To further complicate matters, although pain is largely assessed via subjective reports only, clinicians are often warned not to trust the patients' self-reports of pain. To illustrate, Passik and Kirsch (2007: 443) advise clinicians that "The self-deceiving addicted pain patient's self-report will not help the pain physician; they will inevitably tell a pseudo-addiction tale when queried about why they are out of their medication early". This advice crystallises the moral underpinnings of the concept of pseudoaddiction and the ways in which the clinician is set up as an arbiter of the moral order. 
In this context the clinician's goal is to assess whether the drug-seeking patient is experiencing 'real' pain, or is craving "unauthorised pleasure" (Keane 2008: 5).

The problem of pleasure is also highlighted in discourses on Ritalin - which exhibit a number of intriguing parallels with opiate analgesics. According to Keane (2008: 5):

The issue of pleasure is vital to this management [of the unstable identity of psychoactive drugs], as medical use of psychoactive drugs is justified because it does not produce euphoria or a high, but rather returns the subject to a state of normality... it is the unearned and artificially produced pleasure of the drug user that attracts intense social disapprobation. Therefore in the context of prescribing psychoactive medications to improve health, it is crucial that the corporeal, artificial and excessive pleasures of drug use do not contaminate the therapeutic project.

The desired state of normality that the 'proper' use of Ritalin produces is that of a disciplined, self-regulating and productive child - in contrast to the hedonistic, undisciplined, irrational and pleasure-seeking speed user (Keane 2008). Although one might argue that seeking relief of pain is inherently a pleasurable-seeking aspiration, from a hegemonic standpoint, the 'proper' use of opiate analgesics by 'good' pain patients should similarly be guided by a desire to return to a state of normality that heightens productivity, rather than hedonistic impulse.

It is worth underscoring here that one of the central arguments for viewing pain management as a human right is the elaboration of the economic costs chronic pain entails - particularly in relation to worker productivity losses (see IASP/EFIC 2004; Brennan, Carr \& Cousins, 2007). Thus, access to pain relief often becomes explicitly tied to evidence of the pain patient's worth as a 'productive citizen' (see Meekosha \& Jakubowicz, 1996; Meekosha \& Dowse, 1997; Meekosha, 1999). For example, according to Sees and Clark (1993: 260), “...the patient who is prescribed long-term opioids for pain control may be better able to fulfil major role obligations at work, school, or home than before the opioids were taken" (Sees \& Clark, 1993: 260). Indeed, in the case of S.K. detailed below, decisions to provide access to opioid medication appear to be tied to the fact that "S.K. worked hard and achieved recognition in his field. Opioid treatment of his pain allowed him to fulfil the responsibilities of his position in a public relations firm" (Cohen et al., 2002: S. 105).

\section{Addiction as Aberrance: the Rebirth of an Old Trope}

If clinicians are asked to be moral gatekeepers when it comes to differentiating between legitimate and illegitimate pain patients, they are also required to be legal gatekeepers. According to Rich (2000), physicians and state medical licensing boards have allowed themselves to be conscripted into the war on drugs. Indeed, physician checklists designed to distinguish 'drug seeking' behaviours stemming from undertreatment versus those stemming from an underlying addiction often hinge on distinctions that seem more appropriate to a legal than medical setting. To illustrate, the influential checklist provided in Table 1 was developed by Portenoy (1994), but has been reproduced, with minor variation many times since (e.g. Kirsch et al., 2002; Nicholson \& Passik, 2007). 
Table 1. Examples of behaviours indicative of aberrancy

\begin{tabular}{ll}
\hline Behaviours less indicative of aberrancy & Behaviours more indicative of aberrancy \\
\hline Drug hoarding during periods of reduced symptoms & Prescription forgery \\
Acquisition of similar drugs from other medical sources & Concurrent abuse of related illicit drugs \\
Aggressive complaining about the need for higher doses & Recurrent prescription losses \\
Unapproved use of the drug to treat other symptoms & Selling prescription drugs \\
Unsanctioned dose escalation one or two times & $\begin{array}{l}\text { Multiple unsanctioned dose escalations } \\
\text { Reporting psychic effects not intended by the clinician }\end{array}$ \\
$\begin{array}{l}\text { Stealing or borrowing another patient's drugs } \\
\text { Requesting specific drugs }\end{array}$ & $\begin{array}{l}\text { Obtaining prescription drugs from nonmedical } \\
\text { sources }\end{array}$ \\
\hline
\end{tabular}

Here, "behaviours less indicative of aberrancy" are equated with pseudoaddiction, and are to be seen as evidence that the patient is being undertreated for their pain. On the other side, "behaviours more indicative of aberrancy" are equated with addiction, and are seen as evidence that the patient is seeking drugs for illegitimate purposes. The purpose - and consequence - of such checklists is to aid the clinician in it deciding who needs and deserves drugs for pain and who does not. A close reading of the criteria in Table 1 also reveals an increasing commitment to viewing 'real' addiction as manifested through unsanctioned and illegal behaviours (see also Katz et al., 2007). Seen in this way, it becomes difficult for the clinician to see the 'addict' as anything less than a criminal, while great effort is undertaken to ensure that the 'pain patient' is viewed by the clinician as anything but an 'addict'.

An example of the application of such checklists to treatment decisions based on understandings of 'aberrancy' which conflate addiction and unsanctioned and criminal behaviours can be found in Cohen and colleagues' (2002) case study documenting the case of "S.K.", a 49-year-old male advertising executive with insulin dependent diabetes, lower back pain, diabetic neuropathy, and a distant history of problematic oral amphetamine, cocaine and alcohol use. After discussing the risks of addiction with S.K. and his spouse, his physician prescribed him long- and short-acting oxycodone, with the admonishment that a set number of pills were to be dispensed monthly and a warning that his prescription would not be refilled early if he consumed the medication more rapidly than prescribed. S.K. was subsequently found stealing prescription pads and tearfully explained, "I did not want to get high, I just needed more medicine and I thought Dr. Blank would get angry with me if I asked for more. I did a stupid thing" (Cohen et al., 2002: PS100). However, his explanation that he needed more medication to treat the pain and didn't feel that he could legitimately ask for it was ultimately dismissed.

In the S.K. case study, the distinctions drawn between addiction and pseudoaddiction are not medical but legal. Specifically, it is the illegality of SK's behaviours which made him an 'addict' rather than a 'pseudoaddict'. This conflation of addiction with unsanctioned and criminal behaviours conflicts with emerging public policy responses which view addiction primarily as a health problem mediated by the social and economic conditions of people's lives (Small, 2007; Fisher et al. 2005). Such responses have also become salient in clinical research on problematic substance use, with findings offering increased support for positions that people with addictions require treatment and support, 
not criminalisation and punishment (Shearer et al., 2003; Grabowski et al., 2004; Guttinger et al., 2003; Miller et al., 2004; Drucker, 2001). In fact, calls for access to opiate substitution therapy as both a harm reduction and treatment measure are increasingly being framed as both a public health and human rights issue (see, for example, Canadian HIV/AIDS Legal Network, 2007).

\section{Asserting one Human Right and Negating Another? Human Rights Discourses on Pain and their Implications for 'Addicts'}

Clearly, while calling for access to pain relief as a human right, many pain researchers and clinicians arguing for access to opioid analgesic treatment for 'addicts' have asserted that the realisation these 'rights' ought to occur only when patients are subjected to increased and considerable surveillance. The extension of this human right to 'addicts' therefore implicitly invokes discourses similar to those which would also argue for the withholding of these rights, such as: 'addicts' are not to be trusted, 'addicts' don't seek the right kind of treatment unless they are forced to by others, 'addicts' use drugs for the 'wrong' reasons, and 'addicts' require discipline and surveillance from people in positions of authority 'for their own good'. In this way, the 'addict' becomes separated discursively, clinically and administratively from the 'pain patient', and the contradictions underwriting such rights-based discourses remain invisible: the claims of 'addicts' are deemed illegitimate, requiring a punitive response, while the claims of the pain patient are lauded a major human rights concern requiring an urgent and compassionate response.

According to Brewley-Taylor (2005), such internal contradictions are a key feature of United Nations drug policy more broadly, as the UN's overarching position on human rights is at odds with the rigidly prohibitive ethos of the UN's drug control system and the well established harms of this ethos - to both drug users and non-users. However, the key drug control organ, the International Narcotics Control Board (INCP), is careful to frame its prohibitionist position within the lexicon of human rights, stating:

Protecting the wellbeing of the individual and society is the purpose of prohibiting the non-medical use of drugs, which is certainly not an attempt to limit human rights . . .. The prevention of drug abuse problems by means of national and international control and demand reduction activities can be regarded as a basic human right of the individual and society (in Brewley-Taylor, 2005: 424; emphasis ours).

In this respect it mirrors almost word for word the arguments of pain management advocates.

Harm reduction advocates have stressed the benefits of a human rights approach to addressing drug use (see Ezard, 2001; Hathaway, 2001; Miller, 2001; Hunt, 2004; Canadian HIV/AIDS Legal Network, 2007) in relation to the human rights abuses frequently suffered by people who use illicit drugs (Barrett et al., 2008; Barrett, 2008; Jürgens, 2008) and the human right to use drugs (van Ree, 1999; Hunt, 2004). However, the use of human rights discourses in pain management advocacy supports Keane's (2003: 227-228) comment that: 
While human rights are highly effective tools for argument in some contexts, it is not clear that their mobilisation in the field of drugs will be politically efficacious. In fact, they may work to reinforce a universal model of the 'normal' sovereign individual that pathologises and marginalises drug users.

Citing Johnson, Keane (2003: 230) points out that rights often come in contradictory pairs. Thus, the 'rights' of drug users invariably become pitted against the 'rights' of other groups, such as the presumed 'rights' non-drug users to be protected from societal consequences of illicit drug use. This is precisely what occurs in moves to frame pain relief as a human right, as rights of 'legitimate' pain patients are framed in binary opposition to rights of 'drug seeking addicts'. Therein, the rights of the former formally preclude the rights of the latter.

Conclusions and Implications: Toward a New Understanding of the 'Addict' in Pain Our aim in this paper has been to illustrate the ways in which discourses on pain management and the right to pain relief implicitly serve to further stigmatise people labelled as 'addicts'. Current criminal-legal and regulatory sanctions surrounding the use of opioids have created an environment in which pain management clinicians and researchers are virtually required to frame their 'good' pain patients in opposition to 'street addicts' - and resulting discourses on pain management create a situation in which so-called 'addicts' are demonised and made directly responsible for the 'suffering' of people in pain. This framework is likely to undermine recognition of the pain issues that people labelled as 'addicts' experience, because their pain is automatically delegitimised.

While the undertreatment of pain is a recognised issue amongst pain researchers, we argue that the concept of 'pseudoaddiction' is problematic because it ultimately relies on a clinical judgment that attempts to separate out 'bad' drug seeking addicts from 'good' undertreated pain patients in the face of behaviours that are virtually indistinguishable. Moreover, as we have shown, in this context, addiction becomes conflated with illegal behaviours - a view that has been highly contested in the substance use field. Thus, even when attempts are made to treat pain issues in people with a history of addiction, the overarching climate is one of suspicion, framed by the assumption that 'addicts' are not to be trusted and require discipline and surveillance.

Clearly, assumptions about whose pain is legitimate are as much moral as clinical, and are impacted by judgments about the patient's value as a citizen and contributing member of society. The rhetoric of 'productive citizenship' frames Cohen and colleagues (2002: S105) assertion that "Pain sufferers...live in social context in which they have responsibilities and privileges". However, many people labelled 'addicts' live in social contexts where they are seen to have a responsibility to manage pain 'legitimately', but are provided with none of the privileges or resources that enable them to fulfil this 'responsibility'. Ultimately, efforts to secure access to pain relief as a 'human right' are necessary and urgent, as are efforts to advance social, political, and economic justice for the marginalised and the disenfranchised. However, if access to pain relief is to be a human right, it is a right that must, by definition, extend to all humans - including socalled 'drug addicts'. 


\section{References}

Acevedo, B. (2007). Creating the cannabis user: A post-structuralist analysis of the reclassification of cannabis in the United Kingdom (2004-2005). International Journal of Drug Policy, 18(3), 177-186.

Adams, L.L., Gatchel, R.J., Robinson, R.C., Polatin, P., Gajraj, N., Deschner, M., \& Noe, C. (2004). Development of a self-report screening instrument for assessing potential opioid medication misuse in chronic pain patients. Journal of Pain \& Symptom Management, 27(5), 440-459.

American Pain Society (2007). Definitions related to the use of opioids for the treatment of pain. HYPERLINK "http://www.ampainsoc.org/advocacy/opioids2.htm" http://www.ampainsoc.org/advocacy/opioids2.htm [ Accessed 21 January 2008].

Antaki, C., Billig, M.G., Edwards, D., \& Potter, J.A. (2003). 'Discourse Analysis Means Doing Analysis: A Critique of Six Analytic Shortcomings'. Discourse Analysis Online, $1(1)$.

Barrett, D. (2008). 'Unique in international relations'?: A comparison of the International Narcotics Control Board and the UN Human Rights Treaty Bodies. London: International Harm Reduction Association.

Barrett, D., Lines., R, Scheifer, R., Elliot, R., \& Bewley-Taylor, D. (2008). Recalibrating the regime: The need for a human rights-based approach to international drug policy. London: Beckley Foundation Drug Policy Program and International Harm Reduction Association.

Bhamb, B., Brown, D., Hariharan, J., Anderson, J., Balousek, S., \& Fleming, M.F. (2007). Survey of select practice behaviors by primary care physicians on the use of opioids for chronic pain. Journal of Pain, 8(7), 573-582.

Boyd, S. (2004). From witches to crack moms: women, drug law, and policy. Durham: Carolina Academic Press.

Brennan, F., Carr, D.B., \& Cousins, M. (2007). Pain management: a fundamental human right. Anesthesia \& Analgesia, 105(1), 205-221.

Brewley-Taylor, D.R. (2005). Emerging contradictions between the United Nations drug control system and the core values of the United Nations. International Journal of Drug Policy, 16, 423-431.

Canadian HIV/AIDS Legal Network (2007). Dependent on rights: Assessing treatment of drug dependence from a human rights perspective. Toronto: Canadian HIV/AIDS Legal Network. 
Cheattle, M.D., \& Gallagher, R.M. (2006). Chronic pain and comorbid mood and substance use disorders: a biopsychosocial treatment approach. Current Psychiatry Reports, 8(5), 371-6.

Cohen, M.J.M., Jasser, S., Herron, P.D., \& Margolis, C.G. (2002) Ethical perspectives: Opioid treatment of chronic pain in the context of Addiction. Clinical Journal of Pain, 18(4), S99-S107.

Drucker, E. (2001) Injectable heroin substitution treatment for opioid dependency. The Lancet, 358, 1385.

Elander, J., Lusher, J., Bevan, D., \& Telfer, P. (2003). Pain management and symptoms of substance dependence among patients with sickle cell disease. Social Science \& Medicine, 57, 1683-1696.

Elander, J., Lusher, J., Bevan, D., Telfer, P., \& Burton, B. (2004). Understanding the causes of problematic pain management in sickle cell disease: Evidence that pseudoaddiction plays a more important role than genuine analgesic dependence. Journal of Pain \& Symptom Management, 27(2), 156-169.

Elliott, T.E., \& Elliot, B.A. (1992). Physician attitudes and beliefs about use of morphine for cancer pain. Journal of Pain and Symptom Management, 7(3), 141-148.

Ezard, N. (2001). Public health, human rights and the harm reduction paradigm: From risk reduction to vulnerability reduction. The International Journal of Drug Policy, 12, 207-219.

Fishman, S.M. (2005a). From balanced pain care to drug trafficking: the case of Dr. William Hurwitz and the DEA. Pain Medicine, 6(2), 162-164.

Fishman, S.M. (2005b). The politics of pain and its impact on pain medicine. Pain Medicine, 6(3), 199-200.

Fishman, S.M. (2007) Recognizing pain management as a human right: a first step, International Anesthesia Society, 105(1): 8-9.

Fischer, B., Rehm, J., Brissette, S., Brochu, S., Bruneau, J., El-Guebaly, N., Noel, L., Tyndall, M., Wild, C., Mun, P., \& Baliunas, D. (2005). Illicit Opioid Use in Canada: Comparing social, health, and drug use characteristics of untreated users in five cities (OPICAN study). Journal of Urban Health: Bulletin of the New York Academy of Medicine, 82, 250-266.

Foucault, M. (1979). Michel Foucault: Power, truth, strategy. Edited by M. Morris \& P. Patton. Sydney: Feral Publications.

Foucault, M. (1980). Power/knowledge. New York: Pantheon Books. 
Foucault, M. (1991). The order of things. New York: Vintage Books.

Foucault, M. (1994). The birth of the clinic. New York: Vintage Books.

Foucault, M. (2002). The archaeology of knowledge. New York: Routledge Books.

Frantsve, L.M., \& Kerns, R.D. (2007). Patient-provider interactions in the management of chronic pain: Current findings within the context of shared medical decision making. Pain Medicine, 8(1), 25-35.

Gilson, A.M., \& Joranson, D.E. (2002). U.S. policies relevant to the prescribing of opioid analgesics for the treatment of pain in patients with addictive disease. The Clinical Journal of Pain, 18, S91-S98.

Glajchen, M. (2001). Chronic pain: Treatment barriers and strategies for clinical practice. Journal of the American Board of Family Practice, 14(3), 211-8.

Goffman, E. (1962). Stigma: Notes on a spoiled identity. New Jersey: Prentice-Hall.

Grabowski, J., Rhoades, H., Stotts, A,. Cowan, K., Kopecky, C., Dougherty, A., Moeller, F.G., Hassan, S., \& Schmitz, J. (2004). Agonist-Like or Antagonst-Like Treatment for Cocaine Dependence with Methadone for Heroin Dependence; Two Double-Blind Randomized Clinical Trials. Neuropshychopharmacology, 29, 969-981.

Green, C.R., Wheeler, J.R., \& LaPorte, F. (2003). Clinical decision making in pain management: Contributions of physician and patient characteristics to variations in practice. Journal of Pain, 4(1), 29-39.

Guttinger, F., Gschwend, P., Schulte, B., Rehm, J., \& Uchtenhagen, A. (2003).

Evaluating long-term effects of heroin-assisted treatment: the results of a 6-year followup. European Addiction Research, 9, 73-79.

Hathaway, A. D. (2001). Shortcomings of harm reduction: Towards a morally invested drug reform strategy. The International Journal of Drug Policy, 12, 125-137.

Heit, H.A. (2001). The truth about pain management: the difference between a pain patient and an addicted patient. European Journal of Pain, 5(Suppl. A), 27-29.

Højsted, J., \& Sjøgren, P. (2007). Addiction to opioids in chronic pain patients a literature review. European Journal of Pain, 11, 490-518.

Hook, D. (2001). Discourse, knowledge, materiality, history: Foucault and discourse analysis. Theory \& Psychology, 11, 521-547. 
IASP/EFIC (2004) Global day against pain: IASP \& EFIC's declaration supporting the relief of pain should be a human right. Geneva: International Association for the Study of Pain/European Federation of IASP Chapters.

Jürgens, R. (2008). Nothing about us without us: Greater, meaningful involvement of people who use illegal drugs. A public health, ethical, and human rights imperative. International edition. Toronto: Canadian HIV/AIDS Legal Network, International HIV/AIDS Alliance, Open Society Institute.

Katz, N.P., Adams, E.H., Chilcoat, H., Colucci, R.D., Comer, S.D., Goliber, P., Grudzinskas, C., Jasinski, D., Lande, S.D., Passik, S.D., Schnoll, S.H., Sellers, E., Travers, D., \& Weiss, R. (2007). Challenges in the development of prescription opioid abuse-deterrent formulations. Clinical Journal of Pain, 23(8), 648-660.

Keane, H. (2003). Critiques of harm reduction, morality and the promise of human rights. International Journal of Drug Policy, 14, 227-232.

Keane, H. (2008). Pleasure and discipline in the uses of Ritalin. International Journal of Drug Policy, corrected proof available online 19 September 2007.

Kirsch, K.L., Whitcomb, L.A., Donaghy, D., \& Passik, S.D. (2002) Abuse and addiction issues in medically ill patients with pain: Attempts at clarification of terms and empirical study. Clinical Journal of Pain, 18, S52-S60.

Lin, J.T., \& Mathew, P. (2005). Cancer pain management in prisons: a survey of primary care practitioners and inmates. Journal of Pain \& Symptom Management, 29(5), 466-473.

Lipman, A.G. (2005). Pain as a human right: the 2004 Global Day Against Pain. Journal of Pain \& Palliative Care Pharmacotherapy, 19(3), 85-100.

Martin, A, \& Stenner, P (2004). Talking about drug use: what are we (and our participants) doing in qualitative research? International Journal of Drug Policy, 15(5), 395-405.

McGregor, S.L.T. (2003) Critical discourse analysis: a primer. Kappa Omicron Nu Forum, 15(1).

Meekosha, H. (1999). Disability, political activism, and identity making: a critical feminist perspective on the rise of disability movements in Australia, the USA, and the UK. Disability Studies Quarterly, 19, 4.

Meekosha, H., \& Dowse, L. (1997). Enabling citizenship: gender, disability, and citizenship. Feminist review, Autumn, 49-72.

Meekosha, H., \& Jakubowicz, A. (1996). Disability, participation, and representation in social justice. In C. Christensen \& F. Rizvi (Eds), Disability and the dilemmas of education and justice (pp. 79-95). Buckingham: Open University Press. 
Michna, E., Ross, E.L., Hynes, W.L., Nedeljkovic, S.S., Soumekh, S., Janfaza, D., Palombi, D. \& Jamison, R.N. (2004). Predicting aberrant drug behavior in patients treated for chronic pain: Importance of abuse history. Journal of Pain \& Symptom Management, $28(3), 250-258$.

Miller, P. G. (2001). A critical review of the harm minimization philosophy in Australia. Critical Public Health, 11(2), 167-178.

Miller, C.L., Schechter, M.T., Wood, E., Spittal, P.M., Li, K., Laliberte, N., Montaner, J.S., \& Hogg, R.S. (2004). The potential health and economic impact of implementing a medical prescribed heroin program among Canadian injection drug users. International Journal of Drug Policy, 15, 259-263.

Nicholson, B., \& Passik, S.D. (2007). Management of chronic noncancer pain in the primary care setting. Southern Medical Journal, 100(10), 1028-1036.

O'Brien, C.P., Volkow, N., \& Li, T-K. (2006). What's in a word? Addiction versus dependence in DSM-V, American Journal of Psychiatry, 163(5), 764-765.

Passik, S.D. (2001). Responding Rationally to Recent Reports of Abuse/Diversion of Oxycontin. Journal of Pain \& Symptom Management, 21(5), 359-360.

Passik, S.D., Kirsh, K.L., McDonald, M.V., Ahn, S., Russak, S.M., Martin, L., Rosenfeld, B., Breitbart, W.S., \& Portenoy, R.K. (2000). A pilot survey of aberrant drugtaking attitudes and behaviours in samples of cancer and AIDS patients. Journal of Pain and Symptom Management, 19(4), 274-286.

Passik, S.D., \& Kirsch, K.L. (2007). Commentary on Jun and Reidenberg's 'Physician's being deceived': Aberrant drug-taking behaviors: What pain physicians can know (or should know). Pain Medicine, 8(5), 442-443.

Portenoy, R.K. (1994). Opioid therapy for chronic non-malignant pain: current status. In H.L. Fields \& J.C. Liebeskind (Eds), Progress in pain research and management, volume 1. Pharmacological approaches to the treatment of chronic pain: new concepts and critical issues (pp. 247-287). Seattle: IASP Publications.

Portenoy, R.K. (1996). Opioid therapy for chronic nonmalignant pain: a review of the critical issues. Journal of Pain \& Symptom Management, 11(4), 203-217.

Rich, B.A. (2000). An ethical analysis of the barriers to effective pain management, Cambridge Quarterly of Healthcare Ethics, 9, 54-70.

Room, R. (2003). The cultural framing of addiction. Janus Head, 6(2), 221-234. 
Savage, S.R. (2002). Assessment for addiction in pain-treatment settings. The Clinical Journal of Pain, 18, S28-S38.

Schuster, CR. (1989). Does treatment of cancer pain with narcotics produce junkies? In C.S. Hill Jr. \& W.S. Fields (Eds), Advances in pain research and therapy. New York: Raven Press.

Sees, K.L. \& Clark, H.W. (1993). Opioid use in the treatment of chronic pain: Assessment of addiction. Journal of Pain \& Symptom Management, 8(5), 257-264.

Shearer, J., Wodak, A., Mattick, Richard, P.,Van Beek, I., \& Lewis, J. (2003) Pilot randomized double blind placebo-controlled study of dexamphetamine for cocaine dependence. Addiction, 98, 1127-1141

Small, D. (2007). Fools rush in where angels fear to tread: Playing God with Vancouver's Supervised Injection Facility in the political borderland. International Journal of Drug Policy, 18(1), 18-26.

Sun, V. C-Y.; Borneman, T.; Ferrell, B.; Piper, B.; Koczywas, M. \& Choi, K. (2007). Overcoming barriers to cancer pain management: an institutional change model, Journal of Pain and Symptom Management, 34(4), 359-369.

van Dijk, T. A. (1999). Critical discourse analysis and conversation analysis. Discourse \& Society, 10(4), 439-450.

Van Ree, E. (1999) Drugs as a human right. International Journal of Drug Policy, 10: 89-98.

Weaver, M. \& Schnoll, S. (2002). Abuse liability in opioid therapy for pain treatment in patients with an addiction history. Clinical Journal of Pain, 18, S61-S69.

Weissman, D.E. (1994). Understanding pseudoaddiction. Journal of Pain \& Symptom Management, 9(2), 74.

Weissman, D.E., Gutman, M. \& Dahl, J.L. (1991). Physician cancer pain education: a report from the Wisconsin Cancer Pain Initiative. Journal of Pain and Symptom Management, 6(7), 445-448.

Weissman, D.E. \& Haddox, J.D. (1989). Opioid pseudoaddiction: an iatrogenic syndrome. Pain, 36, 363-366.

WHO (1986). Cancer Pain Relief. Geneva: World Health Organization.

Young, R. Ed. (1981). Untying the text: a post-structural anthology. Boston, MA: Routledge \& Kegan Paul. 
Ziegler, S.J. (2007). Pain, patients and prosecution: Who is deceiving whom? Pain Medicine, 8(5), 445-446. 